\title{
VINILEIROS - A VÍDEO-ETNOGRAFIA DO COLECIONADOR DE VINIL
}

João Pedro dos Santos Fleck ${ }^{1}$

Carlos Alberto Vargas Rossi ${ }^{2}$

O ato de colecionar discos não é um mero passatempo, nem um lazer inócuo. É uma paixão fervorosa que beira a demência... levando estes consumidores a comportamentos extremos, irracionais, compulsivos e fanáticos. (Frank Doris, 1990)

Muitos são os objetos que podem ser colecionáveis. Entre os mais comuns podemos citar filmes, pedras, selos, moedas, chaveiros, cds e discos. Como coleções incomuns, podemos citar as de caixas de fósforo, embalagens de cigarro e tampas de garrafa. Segundo Ehrenfeld (1993) ao menos um em cada três americanos é um colecionador assumido e, adicionando pessoas que guardam registros de acontecimentos e fotografias, podemos dizer que no mínimo metade da América do Norte coleciona.

Para os colecionadores, suas coleções são uma extensão de si mesmos - às vezes simbolizando um aspecto de sua ocupação, herança familiar ou aparência. Segundo Engel, Blackwell e Miniard (2000) as coleções podem tornar-se viciantes e compulsivas, muito embora o processo raramente seja iniciado propositalmente. Cedo as coleções servem como parte do auto-conceito ampliado de alguém, explicando porque ocorrem conversões de profano (comum, incapaz de produzir experiências extasiantes, de autotranscendência e extraordinárias) para o sagrado (mais significativo, poderoso e extraordinário do que o ego) quando o item entra para a coleção. O processo geralmente continua por um longo período, pois a aquisição constante proporciona um sentimento de poder e progresso. O resultado paradoxal é simultaneamente o desejo e o medo de completar a coleção. Entretanto, coleções como de filmes ou de discos são impossível de ser completadas, sendo perenes enquanto forem de interesse do colecionador.

Gelatt (1977) afirma que a introdução do primeiro tipo de disco de vinil no mercado, em meados dos anos 30 foi um fracasso por uma série de razões, sendo que a

\footnotetext{
${ }^{1}$ Universidade Federal do Rio Grande do Sul, Brasil.

${ }^{2}$ Universidade Federal do Rio Grande do Sul, Brasil.
} 
principal era o fato de que o consumidor comum não era capaz de comprar um equipamento reprodutor confiável, em virtude da pobreza advinda da grande depressão.

Mas muitas coisas se alteraram dos anos 30 até os dias de hoje. Em 1948 foi lançado o LP na sua forma mais vendida, alcançando seu pico de vendas em 1977 com a venda de 344 milhões de unidades (Zachary, 1991). Surgiram, então, uma série de outras mídias a partir do final dos anos 70, como a fita K-7, passando pelo CD, até chegar à era da internet, na qual músicas passaram a ser escutadas em mp3, sem existirem fisicamente. E apesar do disco de vinil hoje estar quase extinto, algumas empresas se dedicam a manter a fabricação deste formato, como a Optimal's Record, que tem, aproximadamente, 20\% do seu lucro atual proveniente da venda dos discos de vinil (Williamson, 2006).

Lea (2005) comenta que apesar da indústria da música estar lutando para ser capaz de manter as vendas, os discos de vinil continuavam cultivando (a reportagem é de quatro anos atrás e as vendas seguem aumentando) o mesmo pequeno nicho rentável há mais de uma década. $\mathrm{O}$ autor analisa que, diferentemente dos CDs, o fato das pessoas passarem a fazer downloads de música não influencia negativamente a venda de discos de vinil. O aumento supracitado é notável, pois é a única mídia que apresenta crescimento depois de ter atingido o seu pico de vendas. Segundo dados dessa reportagem, o aumento das vendas de discos de vinil ocorre, pois pessoas jovens estão cada vez mais interessadas nessa mídia, considerada insubstituível por alguns dos depoentes.

Outra reportagem recentemente publicada (Dell, 2008) confirma estes dados e infere que existem muitos jovens e adolescentes (citados na própria notícia como geração Ipod) que estão descobrindo a coleção de discos de vinil de seus pais ou conhecendo essa mídia através dos amigos e acabam por preferi-la por quatro motivos:

- este produto está envolto numa aura retrô, que é muito atraente ao olhar do jovem de hoje em dia;

- a qualidade sonora, muito superior a do MP3 com o qual estão acostumados;

- a qualidade gráfica das capas e dos encartes que acompanham os discos;

- o fato do disco de vinil ser uma mídia mais propícia a ser escutada em conjunto com os amigos do que um mp3.

Na mesma reportagem são apresentados números pertinentes: 990 mil discos de vinil novos foram comercializados no ano de 2007, equivalente a um aumento de 15,4\% em 
comparação com o ano de 2006, onde 858 mil discos foram vendidos. A demanda por discos de alguns artistas está tão grande, neste momento, que Patrick Amory, gerente geral da Matador Records, considera que é impossível produzir em uma escala capaz de acompanhá-la (Dell, 2008).

Além disso, o aumento nas vendas de tocadores de vinil e de discos também foi abordado por Threndyle (1998). Segundo o autor, a preferência pela música escutada em um disco de vinil é um dos principais motivadores que leva esse nicho de mercado a permanecer forte. $\mathrm{O}$ autor analisa que os produtos analógicos oferecem uma capacidade de som que a reprodução digital de música nunca foi capaz de atingir.

Contrapontos interessantes a estas notícias foram publicados em 1991, ou seja, 17 anos atrás. Um deles preconizava que o disco de vinil estava à beira da extinção e que aquele seria um dos últimos momentos no qual este poderia ser comprado (Zachary, 1991). Já o outro, uma declaração, publicada no jornal The Economist na qual a Tower Records, responsável por algumas das maiores lojas de músicas de Londres, anunciava que, em função da demanda por discos de vinil estar muito baixa, estes estariam sendo removidos terminantemente das prateleiras. Atualmente, ao entrar no website da mesma empresa podese constatar não apenas que esta continua comercializando discos de vinil, mas que ela possui aproximadamente 25 mil diferentes álbuns à venda. Muitos dos discos expostos são lançamentos, sendo uma parte considerável destes de bandas que não existiam quando essa declaração foi publicada.

A produtora musical Optimal é um caso clássico de como um nicho de mercado pode ser explorado de maneira realmente satisfatória. A Optimal, uma subsidiária da Edel Music, produz vinis diferenciados, que têm agradado cada vez mais o público. Uma das especialidades é um vinil cor de rosa da Madonna. Outro sucesso de vendas da empresa são os denominados Picture Discs, discos que vem com a imagem da banda impressa. É divulgado, também, que a margem de lucro de um vinil é razoavelmente maior do que a costumeira para um CD, mercado no qual a competição é muito mais ferrenha (Williamson, 2006). Na opinião de Hahn, diretor administrativo de Optimal’s Records, existe um bom número de aficionados em vinis com uma preferência por seu som diferenciado (Williamson, 2006). 
Segundo Williamson (2006), visitar a fábrica de vinis da Optimal é como fazer uma viagem de volta no tempo. Afinal, em um local da empresa encontram-se modernas máquinas produzindo eletronicamente CDs que ficam prontos em menos de 3 segundos e, em outro, encontramos grandes prensas verdes, remanescentes das fábricas de 1970, barulhentas, parecendo trabalhar em um ritmo de antigamente, produzindo um disco a cada 25 segundos.

\section{Sobre a vídeo-etnografia}

O filme realizado é considerado um trabalho pioneiro na área de Marketing no Brasil. A escolha pela realização de uma vídeo-etnografia se deve a um motivo principal: a capacidade deste método de capturar e, principalmente, de expressar um maior conhecimento sobre o sujeito de pesquisa e sobre o trabalho desenvolvido acerca deste (Kozinets e Belk, 2007).

A vídeo-etnografia permite, também, que um trabalho que outrora poderia ter um cunho apenas acadêmico seja apreciável por um público mais amplo. Ao fazer uma análise sobre o uso do vídeo na antropologia visual, Fonseca (1994) infere que o texto escrito era destinado, nove em cada dez vezes, a um público especialista, ao contrário do vídeo, instrumento capaz de iniciar um diálogo sólido e eficaz entre os antropólogos e a sociedade civil. Rial (1994), por sua vez, analisa que é possível realizar vídeos acadêmicos belos que dêem prazer ao espectador e atraiam a sua atenção, conseqüentemente difundindo mais o resultado dos trabalhos de pesquisa realizados.

A pesquisa através do vídeo não se faz presente apenas na comunidade acadêmica. No ano de 2003, ao serem contratados pela Nissan para realizar uma pesquisa sobre brand community, os pesquisadores Schouten e McAlexander foram convidados a entregar apenas material filmado, sem nenhum tipo de acompanhamento textual.

Quanto à vídeo-etnografia aplicada ao Marketing, Kozinets e Belk (2007) defendem

que a nossa vida enquanto consumidores é audiovisual, definida não apenas por pensamentos, atitudes e conceitos, mas também por gestos, cores, formas e sons, e que, portanto, o método vídeo-etnográfico (ou videography, como é tratado pelos autores), permitiria uma maior aproximação com o consumidor. Em outro texto, Belk e Kozinets 
(2005) analisam que este método de pesquisa é mais ligado ao cotidiano do consumidor e permite capturar e expressar mais vividamente a sua realidade.

Russel (1999), por sua vez, analisa o vídeo etnográfico como suscitador de discussões constantes sobre diferentes temas, tais como objetividade, subjetividade, realismo, estrutura narrativa e questões éticas de representação. A autora argumenta ainda que a ligação com as ciências sociais implica em um comprometimento com a objetividade e que o papel do filme é, principalmente, o de se tornar uma evidência empírica. Este comprometimento, porém, é difícil de ser atingido, posto que não há um conjunto de regras estabelecidas para a realização de um vídeo etnográfico.

Segundo Belk e Kozinets (2005), a entrevista filmada tem fortes vantagens sobre aquela que é apenas gravada em áudio ou diretamente transcrita para o papel durante sua realização. Ela permite ao pesquisador a análise da linguagem corporal do entrevistado, além de possibilitar ao pesquisador perceber o tom em que determinada resposta lhe foi dada, possibilitando, assim, uma análise de conteúdo melhor desenvolvida.

Sherry e Schouten (2002) concluem que uma das vantagens mais convincentes da validade deste método é a habilidade de engajar a audiência em um conjunto multisensorial de materiais, facilitando o ganho de um conhecimento não apenas cognitivo sobre determinado assunto, mas também emocional e ressonante.

\section{Preparando o terreno}

Inicialmente foi observado o processo de compra em duas lojas da cidade de Porto Alegre. Em uma delas (loja 1) o dono permitiu que o trabalho fosse realizado e, em aproximadamente trinta horas de observação, perceberam-se alguns detalhes do cotidiano desse ambiente. O dono da outra loja (loja 2) não permitiu que o processo de observação fosse realizado. Entretanto, a inserção do pesquisador na loja foi permitida em função deste estar "supostamente" comprando discos e um total de quatro horas de observação permitiu a obtenção de uma base para comparação.

Percebe-se que o processo de compra é semelhante, mas que existem diferenças marcantes entre os donos. Um deles é muito mais comunicativo (o da loja 2) procura indicar artigos para os clientes, dá descontos constantemente e parece querer eliminar o estoque da loja. Esse lojista, inclusive é apelidado por todos os outros lojistas de "Salim", 
apelido com o qual se diverte bastante. O outro dono (da loja 1) é mais fechado. Atende o cliente com educação, porém, não dá dicas enquanto não conhece o cliente. Acredita que esse tem que ter a liberdade para olhar tudo sem ser importunado. Essa diferença entre os dois é significativa, pois encontram-se aqui dois vendedores peritos, com uma clientela semelhante - por vezes igual - mas que têm uma abordagem bem diferente com o seu público.

As duas lojas têm clientes fiéis, alguns visitando as lojas uma ou duas vezes por semana. Além disso, alguns destes clientes freqüentam a loja por motivações sociais e não por consumo. Eles vão às lojas e passam horas conversando. Alguns se limitam a conversar apenas com o dono, outros conversam entre si e outros, às vezes não tão benquistos pelos lojistas, conversam com qualquer cliente que apareça na loja, inclusive atrapalhando algumas compras.

Em alguns momentos, foi observado que a loja 1 fica vazia durante mais de uma hora inteira, sem nenhum cliente. Em um desses momentos o dono comenta, espontaneamente:

É. As vezes é assim mesmo. O movimento fica fraco. Fica uma ou duas horas sem entrar ninguém. Agora é assim. Não dá para ganhar dinheiro MESMO, dá para sobreviver. Antigamente o pessoal comprava bem no início do mês, entrava algum legal, agora é diferente. O final do mês é ruim, mas o início não é bom. Não sei como os caras trabalham com sociedade e com funcionários. Agora no máximo dá para ter dois sócios e os dois trabalhando juntos, ou um empregado. Senão não dá para ganhar dinheiro algum. (Luís)

A loja em questão (loja 1) é uma das mais organizadas de Porto Alegre, possui aproximadamente 5 mil CDs à venda e mais de dez mil discos de vinil, estes variando de valor entre três e trezentos reais, sendo citada por diversos respondentes como a sua loja preferida para a compra de vinis. Os discos estão organizados por gênero, e dentro do gênero por ordem alfabética. Dificilmente as lojas de CDs novos possuem uma organização tão bem desenvolvida quanto a que essas lojas de vinis oferecem.

Uma interessante conversa entre o dono da loja 1 e um amigo esclarece a respeito do tempo que o lojista chega a ficar com um disco na loja antes de vendê-lo. O lojista comentou:

Sabe com quantos CDs eu comecei a loja? 38! 38 CDs! Tenho até foto para documentar. Tem muita coisa que eu compro e fico por 4, 5 anos sem vender. $O$ giro é muito baixo. Mas é assim, eu tenho que comprar, porque se eu não comprar eu não tenho o que vender, né? (Luís) 


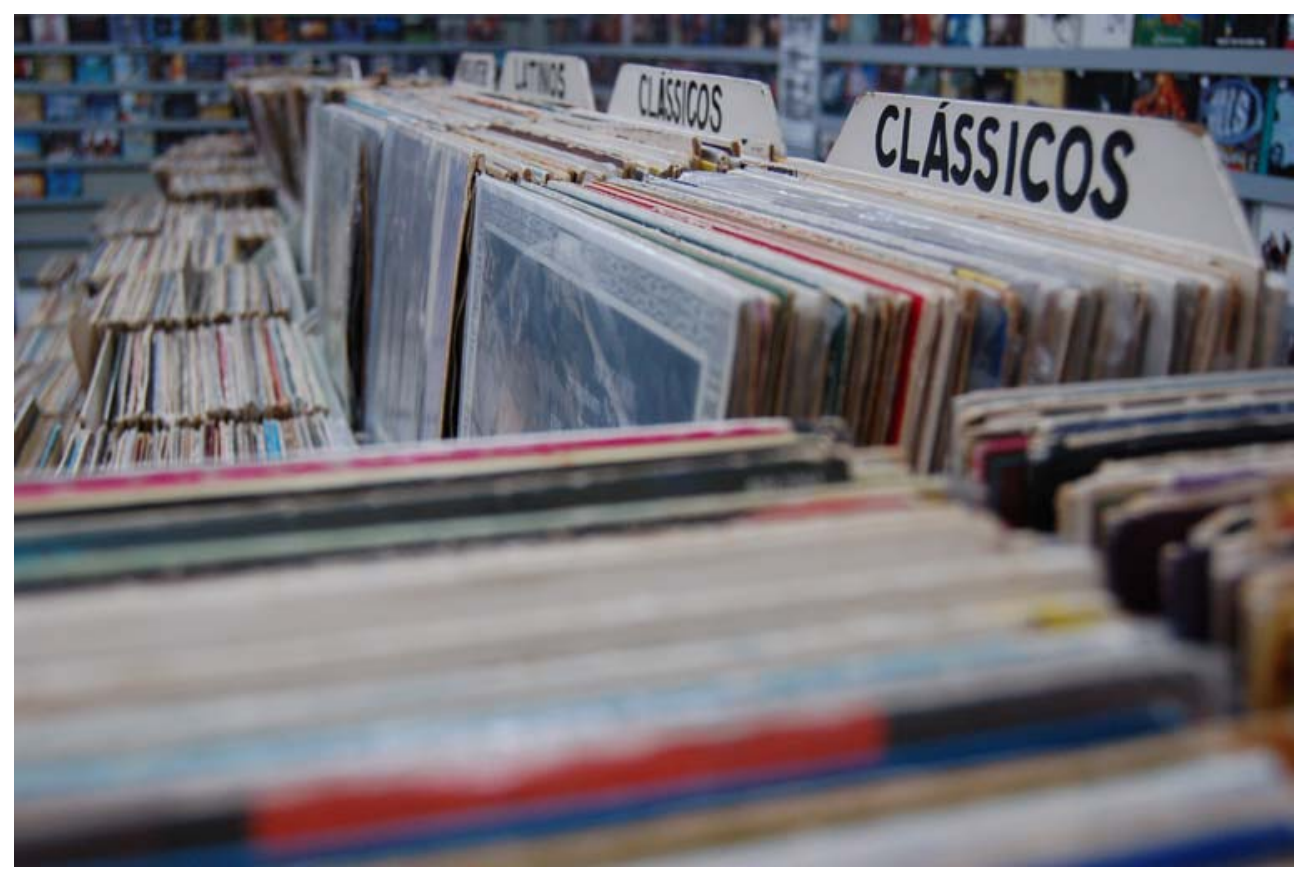

Figura 1: Foto da Loja 1

\section{Curiosidades do mercado de vinil}

Existem duas principais gírias utilizadas pelos lojistas. Essas palavras são: a "pedra” e o "lote” ou o "lotezinho". A “pedra” é utilizada para se referir aos vendedores que vendem os discos expondo-os no chão do centro da cidade, em geral à noite ou nos finais de semana. O lojista 1, inclusive, possui uma espécie de funcionário a quem ele fornece uma pequena quantidade de discos para que ele exponha e venda na “pedra” toda a noite no centro de Porto Alegre.

Já o "lote” é referente quase sempre a um conjunto de discos de vinil, e são negociações em geral tratadas com sigilo, pois essas são as maiores preciosidades que esses lojistas podem conseguir. Em uma das visitas à loja 1, presenciou-se a perda de um lote de CDs raros por um preço baixo porque a vendedora ofereceu seu lote enquanto o lojista estava em seu horário de almoço. Após o acontecimento, o próprio lojista comentou:

Pois é... Agora o cara não pode nem mais almoçar que ele já perde um lote. A guria veio na hora do meu almoço e já era. Devo ter perdido o lotezinho para algum outro. Bom, pelo menos esse que eu perdi era de CDs. Um lote de vinilzinho raro um cara não pode perder. Um lotezinho desses é uma boa. (Luís) 
Alguns clientes aparecem na loja 1, dedicada apenas a venda de CDs e LPs, procurando por agulhas, vendidas na mesma galeria, mas em outro andar. O dono informa onde eles podem encontrar e avisa de antemão que algumas agulhas já não mais são fabricadas. Comenta, logo após a saída do cliente: “O que vai matar o vinil algum dia é isso aí. Não é a existência do CD ou do MP3, mas a falta de agulhas de qualidade disponíveis no mercado”.

Por fim, a característica que chama especialmente a atenção nas duas lojas pesquisadas e que aparentemente é semelhante nas outras lojas de discos usados da cidade: elas parecem estar deslocadas no tempo e fora da realidade em que estão inseridas. Esta inferência é baseada no fato de nenhum dos clientes que tiveram o processo de compra acompanhado (e até mesmo o de venda ou troca) estar com pressa. Alguns dos clientes passam mais de uma hora comprando discos, sendo que um número significativo desses permanece na loja apenas avaliando atenciosamente as mercadorias em exposição, sem realizar nenhuma compra. As pessoas verdadeiramente se dedicam ao processo de compra dos discos, elas não querem um "comércio rápido”. Algumas dão a impressão de querer olhar toda a loja, sem exceção, passando disco a disco, para analisarem precisamente o que é do interesse delas.

\section{Sobre as filmagens}

A realização das filmagens se deu ao longo de um período total de 3 meses (entre agosto e outubro de 2007). Foram entrevistados 31 colecionadores de discos, dentre os quais 12 foram selecionados para participar da versão final do curta-metragem etnográfico "Vinileiros".

Encontrar esses 31 respondentes foi uma das tarefas mais árduas do desenvolvimento da pesquisa. Isso se deve ao fato de ter sido estipulado o número arbitrário de 200 discos para que a pessoa fosse considerada “colecionadora”. Número esse ignorado em apenas uma das entrevistas, pois, ao saber da realização do trabalho, um colecionador com apenas 85 discos insistiu veementemente para ser entrevistado, argumentando que seus 85 discos eram muito mais significativos para ele como colecionador do que para pessoas com coleções muito maiores. 
Poucos respondentes foram encontrados em lojas e filmados no próprio local de compra (aproximadamente 5). O restante (26) foi encontrado pelos pesquisadores em uma busca detalhada em um site de rede de contatos virtual (orkut) e foram filmados em sua casa ou em seu local de trabalho.

No total foram coletadas aproximadamente 8 horas de filme, que foram editadas, gerando um curta-metragem documental de 24 minutos.

\section{O Filme}

Diferentes trechos de literatura marcam os diferentes capítulos do filme. O primeiro trecho, de Oswaldo Teixeira (1954) afirma que colecionar é uma arte. "É a arte de perpetuar as coisas, de prolongar e dar maior sentido de vida espitural a tudo aquilo que, por vezes, aos outros não tem valor algum”.

Para a abertura do documentário, foram selecionados momentos que identificassem cada um dos respondentes, como uma espécie de apresentação de cada um deles, tais como:

"Se eu coleciono é porque eu gosto, porque eu tenho amor pelas coisas”(Janaína); "Eu gosto de ficar admirando a capa assim, o encarte” (Rafael); "Uma maneira de eu viver a adolescência dos anos 70 e resgatar essa saudade do que eu não vivi é colecionando discos" (Alcione) e "É um livro da vida da gente né cara, todo disco tem uma época, uma etapa” (Luiz Ernesto).

Logo após esses breves depoimentos, era inserido uma apresentação em texto de cada um dos participantes, indicando seu nome, idade, profissão e número de discos em sua coleção (que variou entre 85 e 12 mil).

O segundo capítulo do filme é marcado por um trecho de Frank Doris (1994), que diz que colecionar discos não é um mero passatempo, nem um lazer inócuo. É uma paixão fervorosa, que beira a demência, levandos estes consumidores a comportamentos extremos, irracionais, compulsivos e fanáticos. A temática central desse segundo capítulo, portanto, é a coleção per se e o envolvimento dos colecionadores com esta.

Alguns colecionadores de vinil porto-alegrenses comentam como as suas coleções começaram, em alguns casos tendo surgido como uma herança, um prolongamento da coleção dos pais, ou simplesmente o início da coleção tendo se dado em função de ver os pais ouvindo discos. Dois outros entrevistados admitem que começaram sem possuir essa 
influência e disseram que "foram comprando" para só posteriormente assumirem-se como colecionadores. Um deles disse ter percebido isso quando atingiu os 100 discos e o outro se refere ao número de 100 discos em sua coleção como determinante para iniciar seriamente o processo de coleção, que para ele significava a organização e catalogação dos seus discos.

Também nesse capítulo é comentado a importância e o valor desse patrimônio (discos) nas suas vidas, com comentários a respeito de como um dos entrevistados gostaria de emoldurar os seus discos e como, para outro, certos discos hoje são apenas para ficar guardados, a fim de evitar o seus desgaste. São feitos comentários sobre como os discos simbolizam escolhas e a valorização das diferentes gravações de uma mesma música, dos sentimentos despertados por esse objeto, entre eles o carinho e o fetiche, além, e especialmente, do cuidado que os colecionadores tem com seus discos. Tais características podem ser percebidas nos seguintes trechos: "Tanto é que eu tô sempre tratando com carinho, né, to sempre cuidando, limpando” (Sérgio), “Se tu não se sentir muito ligado a eles, eles se deterioram rápido” (Alcione) e "Eu não tenho animal de estimação, mas os meus discos são meus animais de estimação, como eu digo” (Vasquez).

O disco de vinil é a única mídia que passa a apresentar um crescimento significatico nas vendas anos depois de ter atingido o seu pico e esse aumento ocorre em parte, em função de jovens compradores é a frase de Lea (2005), que dá início ao terceiro segmento de Vinileiros. Este trecho do filme compreende os depoimentos sobre o momento da compra dos discos.

Um dos colecionadores (que é também comerciante de discos de vinil) corrobora o texto de Lea, afirmando haver muita gente nova comprando vinil e que este nunca deixou de ser fabricado, tanto no exterior, quanto no Brasil. Já outro comenta como em 2007 um determinado lançamento teve as suas 10 mil unidades esgotadas rapidamente, mostrando como este objeto ainda se faz presente ativamente no mercado.

Um dos colecionadores atesta que o melhor lugar de todo Brasil para se comprar discos é a cidade de Porto Alegre e outro fala sobre as jornadas que ele fazia, indo de Imbituba para Florianópolis de carona apenas para poder comprar seus discos. São também mencionadas aqui dificuldades que os colecionadores passaram comprando discos, sendo que dois depoentes comentam do dilema ao se escolher quais títulos levar em uma situação em que se sabia que aqueles discos não seriam encontrados novamente. 
Menções são feitas sobre o prazer (sendo que um deles dá a entender que esse prazer só é inferior ao orgasmo) e a satisfação ao adquirir um disco, por vezes suplantada somente pelo ato de escutar o disco, principalmente pela primeira vez, encarado por alguns como um ritual a ser bastante apreciado. O valor da coleção e o significado dessa compra são facilmente compreendidos a partir do comentário de Rafael: “É a coisa mais valiosa que eu tenho assim, é uma coisa minha assim né, que eu gosto mesmo assim de olhar, uma coisa que eu não comprei por obrigação ou necessidade assim”.

Por outro lado, existe também a insatisfação que eventualmente é causada pelo tempo despendido na busca de um determinado LP, fato relacionado diretamente com a escassez de determinados títulos no mercado, que por sua vez acaba levando à resignação dos colecionadores. Estes acabam por se resignar a pagar mais, sendo que uma colecionadora fala de como um item necessário para fechar a coleção de um determinado artista passa a ser mais valioso para ela, fazendo com que ela pague mais por ele sem problema algum. O colecionador de maior expertise fala sobre como tem realmente preços espantosos de discos, como o primeiro LP do Roberto Carlos, que vale 13 mil reais.

Com relação às lojas, são feitos comentários sobre como é possível encontrar artigos raros de modo inusitado em lugares como brechós, por exemplo, e, também, sobre o desconhecimento dos vendedores com respeito à raridade dos discos, em alguns casos, só sendo percebida por um comprador muito bem informado. Alguns lojistas, na opinião dos entrevistados, parecem estar apegados a determinados discos e colocam valores para que estes não sejam comprados nunca, já outros aumentam o valor dos discos na esperança de capitalizar um lucro maior em cima do fetiche dos compradores.

Comentários interessante são feitos sobre como as economias, mesadas e salários dos colecionadores é direcionada na integralidade para aquisição dos discos de vinil. Tais como: "Já economizei muito, já deixei de ir a jogo, deixei de comprar bola de futebol e de ir em boate para comprar o último disco do Rush ou alguma coisa assim” (Luiz Ernesto), “No começo, quando era mesada ainda, era o negócio de pegar a mesada, vir para Porto Alegre e comprar um vinil, dois, três, o que dava” (Arthur); “Cheguei ao tempo de no primeiro trabalho, e do outro lado da rua tinha uma loja que nem existe mais, A Rede, e bem na frente tinha o setor de vinil e eu cansei de atravessar, no dia do pagamento, entregar 
todo meu salário e levar uma pilha de discos para casa e me considerar o garoto mais feliz” (Darci).

O quarto segmento do filme se inicia com a opinião de Threndyle (1998) que infere que o som do vinil é mais rico, como algo que vem de dentro e você pode experienciar todas as nuances da música. O bom vinil é como um bom vinho. Ele tem um bouquet especial. Aqui, o ponto principal discutido é a comparação do disco de vinil com o CD.

Alguns entrevistados falam sobre como trocaram todos os seus discos de vinil pelos CDs em um primeiro momento. Alguns questionam ainda a qualidade de som entre o cd e o vinil, como Sérgio: “eu não consigo achar que CD, aquele pequenininho ali, seja melhor” e Alcione e Sérgio contam a mesma história, sobre como um dia eles ouviram o mesmo álbum em vinil e em $\mathrm{CD}$, pois pretendiam passar a escutar o disco apenas em $\mathrm{CD}$ a fim de preservar o disco de vinil. Esse teste os fez perceber que no CD o som do baixo e da percursão havia desaparecido e que o som estava mais abafado. Ambos decidiram sempre que possível escutar os álbums em disco de vinil, sendo que Alcione encerrou seu argumento afirmando que para ele CDs eram um lixo e que a partir daquele dia não iria pensar em comprá-los novamente.

Essa comparação também é comentada por outros colecionadores: “a mixagem do vinil era melhor” (Eduardo); “o cd te corta muita coisa e o vinil é mais autêntico, ficando como foi gravado originalmente” (Vasquez); “já me explicaram tecnicamente isso, mas isso é que é o encanto do vinil, ele tem um tipo de som que faz o do CD parecer ser pasteurizado, parece que ele é empacotado assim” (Luiz Ernesto); “tem o fetiche da coisa mais crua, o som do vinil é mais cru, é mais quente e tal, isso não é um delírio de um aficcionado, isso existe" (Arthur). Vasquez complementa com a seguinte metáfora: "é como tu tomar um café, vamos dizer assim, com aqueles coadores antigos, e tu tomar um café de máquina hoje. Para mim ele não tem o mesmo sabor.”

Os entrevistados comentam também a respeito de algumas sutilezas que tornam essa diferença tão significativa, tais como: o peso do disco na mão, o romantismo que está ligado à mídia, a emoção de virar o disco e a existência dos dois lados, o charme do vinil, o glamour da capa e do encarte. Sendo que Alcione comenta: “a capa do vinil já era parte do trabalho dos caras, sabe. A ordem que tu escolhia cada música já era parte do trabalho, parte do que tu queria dizer”. 
O chiado proveniente do vinil foi abordado por três dos respondentes. Arthur acredita que ele tem um charme, enquanto o chiado proveniente de um CD é insuportável. Vasquez acha que até mesmo o chiado do vinil é algo que contribui para tornar essa mídia mais autêntica e Rafael comenta que apenas vinis arranhados tem chiado, vinis bem conservados, tocados em um bom equipamento, não tem.

A respeito da indústria, surgiram os seguintes depoimentos: "o rolo veio, o K7 veio, o CD veio e vão desaparecer, podem vir coisas mais modernas, mas o vinil vai permanecer" (Vasquez); "o ideal para a fábrica teria sido: vamos partir para o CD e esquecer isso daqui que o vinil está superado. Erraram. O vinil não vai morrer, eu tenho a impressão” (Eduardo); "tem muitas coisas que não existem e nunca vão existir em CD, mesmo que a tecnologia dure 200 anos, nunca vai existir. Simplesmente pela falta de interesse, pela falta de sensibilidade de se ter em CD” (Alcione).

O quinto trecho do filme trata do ato de colecionar e abre com o trecho de Engel Blackwell e Miniard (2000) que infere que as coleções são paradoxais pois englobam simultaneamente o desejo e o medo de completar a coleção. Entretanto, coleções como a de filmes ou de discos são impossíveis de serem completadas, sendo perenes enquanto forem de interesse do colecionador.

Nessa linha de pensamento, alguns entrevistados comentam sobre como acham que suas coleções nunca estarão completas: "até os 200 discos eu tinha essa ilusão de que eu poderia completar, de que eu poderia esgotar a MPB dos anos 70 assim” (Alcione); “é impossível que eu tenha todos os discos do mundo e eu acho que uma coleção para ser completa seria se tu possuísse tudo aquilo né” (Janaína); “o colecionador nunca vai dizer que tá completo, sempre vai ter alguma coisa a mais, sempre vai ter” (Luiz Ernesto); “daqui a pouco tu vê numa vitrine, tu ouve num rádio, na internet. Sempre vai te despertar o interesse por um próximo item” (Darci); “coleção não se completa, não se termina nunca (Vasquez).

O apego com os discos é comentado por Arthur, que afirma nunca ter cogitado se defazer de sua coleção, e por Vasquez, ao dizer que já se separou de mulheres e saiu de casa, mas que não se separa dos seus discos. Alguns ainda falam que pretendem deixar seus discos para os seus filhos, ou doar eles para uma instituição cultural, onde eles venham a ser melhor aproveitados. 
A possível perda da coleção de discos é um dos pontos que mais desperta a sensibilidade e que esclarece o significado dos discos para um colecionador, conforme fato narrado por Luiz Ernesto:

\begin{abstract}
Vou contar um causo, como diz o gaudério... E houve uma enchente lá em Novo Hamburgo. Dessas coisas aí que a água invade e ela invadiu a casa de um amigo. E os discos dele estavam todos no chão assim, sabe. Ele perdeu a coleção praticamente toda. E ele uma vez, num churrasco com a gente, ele falou uma coisa que eu entendi logo, alguns ficaram pensando. Que depois daquele dia ele tinha perdido a identidade. (Luiz Ernesto)
\end{abstract}

O segmento que encerra o filme é o que versa sobre a importância da coleção e sobre a conexão existente entre o ato de colecionar discos de vinil e o sentimento de nostalgia. Um trecho de uma música dos Buzzcocks, de 1954, de autoria de Pete Shelley abre este segmento: "I always used to dream of the past, but like they say yesterday never comes. Sometimes there is a song in my brain and I feel that my heart knows the refrain. I guess it is just the music that brings on nostalgia for an age yet to come”.

O depoimento de Eduardo define claramente o que é o disco na visão dos colecionadores: "É uma coisa que transcende a matéria obviamente né, porque não é só o plástico que toca um som que é importante para ti, que marcou a tua vida...”. Ele ainda afirma se lembrar de cada ano em função das músicas que ao longo dele foram lançadas. Muitos colecionadores também acreditam que seus discos reforçam sua personalidade, conforme relata Alcione: “a coleção é a trajetória de vida de uma pessoa, é algo que tu agrega no teu dia a dia, em termos do que tu gosta, do que tu conhece, das pessoas que passam a conhecer tua coleção e gostar das coisas”.

A nostalgia foi bastante comentada. Para Eduardo, este sentimento é responsável por uma fatia do mercado dos colecionadores de vinil, já. Rafael afirma que a maioria das músicas que ele escuta foram gravadas antes do seu nascimento e Fábio expõe que seus discos o remetem ao passado. Karina admite se sentir nostálgica pois as músicas são em geral de décadas passadas e o vinil também é lembrado como uma mídia retrógrada. Alcione corrobora com esse pensamento, admitindo que é muito nostálgico e que gostaria de ter nascido há 30 anos.

Alguns dos entrevistados tem lembranças profundas relacionadas a música, seja sobre a época da infância em que gravavam fitas K7 com programas de rádio, sobre o 
primeiro disco de vinil que compraram, ou sobre a primeira vez que escutaram rock'n'roll, sentido-se despertados por determinada música.

\section{Considerações finais}

O presente trabalho não se propõe a ser conclusivo, mas, sim, analítico, colaborando para o avanço do conhecimento sobre o consumo de coleção e abordando também questões do comportamento de compra. O vídeo aqui analisado apresenta as características essenciais do universo dos colecionadores de vinil, ou seja, o significado destes objetos, a influência da nostalgia, a memória que está atrelada a eles e a sua importância para o colecionador.

É interessante ainda frisar que a vídeo-etnografia tem como benefício principal a possibilidade de difundir o conhecimento desenvolvido no meio acadêmico para o público. Afinal, o uso do vídeo permite ao pesquisador apresentar, de um modo mais palatável, o resultado de seu trabalho. Uma vez desenvolvido um filme etnográfico atrativo, este pode vir a ser exibido em festivais de cinema, em canais de televisão ou disponibilizado na internet, atingindo pessoas que, de outra maneira, não teriam acesso a estas informações.

As análises apresentadas corroboram com os conhecimentos acumulados, indicando que o consumo de coleção realmente torna um objeto outrora cotidiano em um objeto que ocupa um espaço especial na vida do colecionador, levando-o a abrir mão de seu tempo e de seu capital na busca e aquisição da próxima peça procurada. Os colecionadores entrevistados têm o disco de vinil como um objeto precioso e isso deve ser respeitado por pessoas que não conhecem essa realidade. Em um determinado momento do vídeo, um entrevistado comenta como pessoas não iniciadas no mercado de vinil se surpreendem com o valor de determinados artigos. Porém, com base nas entrevistas, pode-se perceber que não apenas o valor financeiro dos discos é surpreendente, mas também o valor agregado e a importância dos discos na vida dos colecionadores, superior a diversos outros objetos e até mesmo a animais de estimação ou a um relacionamento amoroso.

Podemos afirmar que o forte envolvimento entre o colecionador de vinil e seus discos é o que permite às empresas produtoras e comercializadoras de discos de vinil manterem sua rentabilidade ao longo de tantos anos e apresentando crescimento na última década. Por fim, é importante salientar, com base no conhecimento acumulado ao longo 
deste trabalho, que este colecionador é um consumidor verdadeiramente dedicado ao seu produto de consumo, consumindo-o repetidamente, fazendo dele uma extensão de si, e que, por tais características, se sobressai dentre os demais.

\section{REFERÊNCIAS}

BELK, Russel W. e KOZINETS, Robert V. Videography in marketing and consumer research. Qualitative Market Research: an international journal. Vol. 08, N. 02, 2005.

DELL, Kristina. Vinyl gets its groove back. Time. New York: Vol. 171, Iss. 3; pg. 55; Jan 21, 2008.

DORIS, Frank. Searching Out an Endangered Species, In: FD's Newest Hunting Tips. The Absolute Sound, Issue 65, May/June 1990.

EHRENFELD, Temma. Why Executives Collect. Fortune. New York: Jan 11, 1993. Vol.127, Num. 1; p. 94.

ENGEL, James F.; BLACKWELL, Roger D.; MINIARD, Paul W. Comportamento do consumidor. Rio de Janeiro: Livros Técnicos e Científicos S.A., 2000.

FONSECA, Claúdia. Vídeo e etnografia: perguntas que pairam no ar. Boletim da ABA Federação Brasileira de Antropologia. N. 21, Fevereiro/1994.

GELATT, Roland. The fabulous phonograph. New York: MacMillan, 1977.

KOZINETS, Robert V. e BELK, Russell W. Camcorder society: quality videography in consumer research In: BELK, Russell W. (ed.) Handbook of qualitative research methods in marketing. Cheltenham, UN and Northampton, MA: Edward Elgar Publishing, 335-344, 2006.

LEA, Jason. Vinyl record aficionados keep niche alive. Plastics News. Vol. 17, Issue 25, p15, 2005.

RIAL, Carmem Silva, Antropologia Visual em Nova Fase. Boletim da ABA - Federação Brasileira de Antropologia. N. 21, Fevereiro/1994.

RUSSEL, Catherine. Experimental ethnography: the work of film in the age of video, Duke University Press, 1999.

SHERRY, John F. e SCHOUTEN, John W. A role for poetry in consumer research, Journal of Consumer Research, Vol. 29, N. 2, 2002

THRENDYLE, Steven. The vinyl word in music: just when you thought you had the ultimate in CD stereo systems, it's time to start buying turntables and tube amps again. Canadian Business. Toronto: vol. 71, Iss. 4; pg. 92; Mar 13, 1998.

WILLIAMSON, Hugh. Record profits from modern-day nostalgia niche markets. Financial Times. London: p. 12; Mar 29, 2006.

ZACHARY, G. Pascal. Many record fans say vinyl LPs are groovier than CDs - they are buying the albums as if they are going out of style - and they are. Wall Street Journal. (Eastern edition). New York, N.Y.: May 9, 1991. 